\title{
Strain Patterns in Charpy Impact Specimens Of 0.20 Pct C Mild Steel
}

\author{
by E. S. Bumps
}

\begin{abstract}
A series of macrographs are presented for the purpose of graphically recording the strain phenomenon that accompanies the energy transition in the Charpy impact testing of a mild steel that is susceptible to strain aging.
\end{abstract}

$S^{\mathrm{T}}$ TRAIN patterns in mild steel Charpy impact specimens were obtained in order to determine whether, on the first appearance of plastic strain during deformation, the initial fracture cracks appear in the region of plastic strain or in the elastically deformed regions between. Although this attempt to locate the initiation of cleavage was not successful, the observed strain patterns illustrating various stress conditions in partially deformed Charpy specimens are presented along with a discussion of the possible dependence of transition energy on the yield phenomenon.

Earlier work on the development of strain patterns in mild steel have been reported by $\mathrm{Fry}^{1}$ and later by Jevon. ${ }^{2}$ Harris, Rinebolt, and Raring ${ }^{3}$ observed characteristic strain markings on the surface of Charpy V-notch impact specimens fractured above and below the transition temperature which they presented schematically. It is intended that the strain figures presented here will add to the literature a graphic correlation of strain with transition energy in impact specimens.

Samples of $5 / 8$ in. round hot rolled, 0.20 pet $C$ steel were machined to standard 0.394 in. sq, Vnotch Charpy impact specimens. Preliminary testing involved determination of transition temperature, Fig. 1, using a Sontagg impact tester. These data were subsequently used to select temperatures above, within, and below the transition range at which specimens were partially deformed. Partial deformation was obtained by either varying the energy or the testing temperature, see Table I.

Macroscopic strain figures shown in Figs. 2 to 19 were produced by several metallographic repolishing and etching steps. The macroetchant used was as follows: ${ }^{4} 120 \mathrm{~g} \mathrm{HCl}$, concentrated; $100 \mathrm{ml}$ water; and $90 \mathrm{~g}$ cupric chloride. Strain figures were obtained on the outer surface and on sections through the central portion of the impact specimens in order to determine an approximation of the volumetric strain pattern. In the tensile strain figures reported by Jevon, it was found that strain etching would not work immediately following strain unless the material was heated to $200^{\circ} \mathrm{C}$. The impact strain

E. S. BUMPS, Junior Member AIME, formerly Research Metallurgist, Armour Research Foundation, Chicago, is now Metallurgist, Studebaker Corp., South Bend, Ind.

Discussion on this paper, TP 3357E, may be sent, 2 copies, to AIME by Dec. 1, 1952. Manuscript, April 4, 1952. Philadelphia Meeting, October 1952.

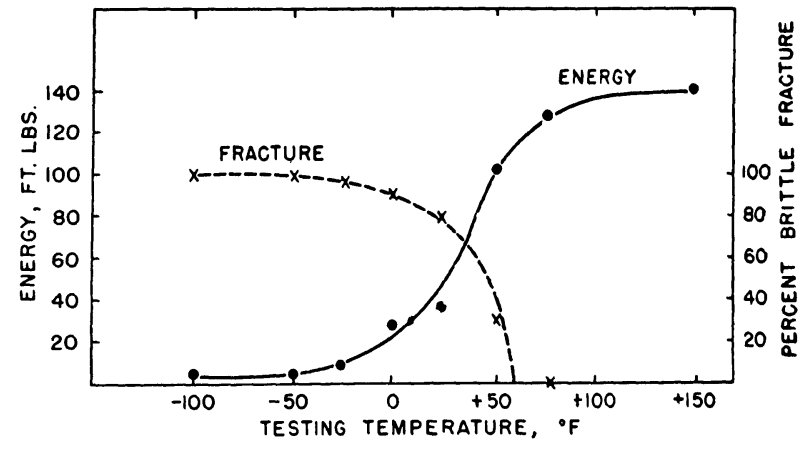

Fig. 1-Energy and fracture curves for 0.20 pct $\mathrm{C}$ mild steel.

patterns presented here were obtained without this heating, but the specimens were not etched until ten months after straining. This confirms a discussion of Jevon's paper, in which it was pointed out that strain figures can also be developed after aging for long periods of time at room temperature. Hardness of the strained and unstrained portions, revealed by the etched pattern, was explored using $R_{F}$ impressions converted to $R_{B}$ hardness values.

\section{Discussion of Results}

In the impact test, as in the tensile test, some parts of the specimen yield and deform plastically, while other regions are deformed only elastically. The plastic deformation bears a relation to the imposed stress pattern. In the strain figures presented here, the plastically deformed regions are the dark etching ones. The strain figures are always symmetrical because the stress state in the Charpy-type specimen under impact loading is symmetrical.

The difficulties encountered to produce initial cracks are intimated in Figs. 2 and 4 . At a temperature of $-75^{\circ} \mathrm{F}$, the stress was not sufficient to pro-

Table I. Testing Conditions for Partially Deformed Mild Steel Charpy Impact Specimens

\begin{tabular}{|c|c|c|c|c|}
\hline $\begin{array}{c}\text { Speci- } \\
\text { men } \\
\text { No. }\end{array}$ & Capacity & $\begin{array}{c}\text { Testing } \\
\text { Tempera- } \\
\text { ture, } \\
\text { oF }\end{array}$ & $\begin{array}{c}\text { Angle of } \\
\text { Deformation }\end{array}$ & $\begin{array}{l}\text { Fig. } \\
\text { No. }\end{array}$ \\
\hline $\begin{array}{l}\text { XA3-9 } \\
\text { XA3-2 } \\
\text { XA3-1 } \\
\text { XA3-4 } \\
\text { XA3-8 }\end{array}$ & $\begin{array}{l}\text { Hammer raised approxi- } \\
\text { mately } 12 \text { in. } \\
\text { Hammer raised } 121 / 2 \mathrm{in} . \\
25 \mathrm{ft} \mathrm{lb} \\
25 \mathrm{ft} \mathrm{lb} \\
60 \mathrm{ft} \mathrm{lb}\end{array}$ & $\begin{array}{r}-75 \\
-75 \\
-12 \\
0 \\
+27\end{array}$ & $\begin{array}{c}0^{\circ} \\
\text { Broke } \\
2^{\circ} \\
14^{\circ} \\
33^{\circ}\end{array}$ & $\begin{array}{c}2 \\
4 \\
5-9 \\
10-14 \\
15-19\end{array}$ \\
\hline
\end{tabular}




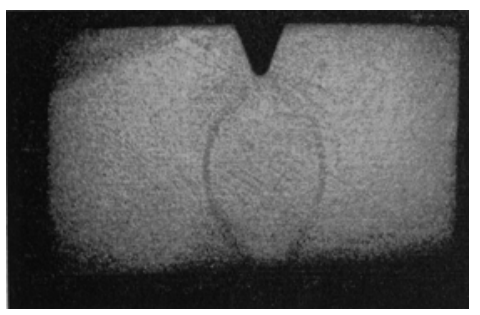

Fig. 3-Same specimen as Fig. 2 showing $R_{B}$ hardness (Rockwell $F$ impressions converted to Rockwell $B$ hardness number). X21/2.

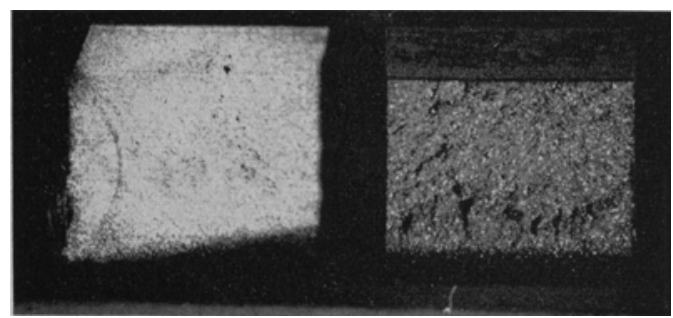

Fig. 4-Strain pattern and brittle fracture surface in specimen broken at $-75^{\circ} \mathrm{F}$. Hammer was lifted approximately $1 / 2$ in. higher than for partially deformed specimen shown in Fig. 2. X21/2.

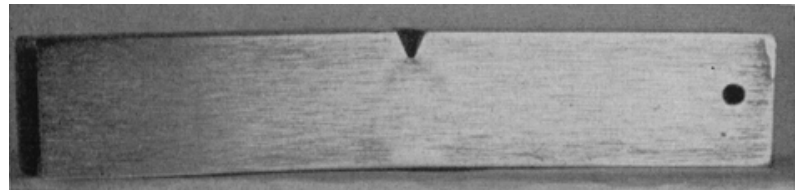

Fig. 5-Partial deformation in a mild steel Charpy impact specimen tested at $-12^{\circ} \mathrm{F}, 25 \mathrm{lb}$ capacity. $\mathrm{X} 2$. Area reduced approximately 40 pct for reproduction.

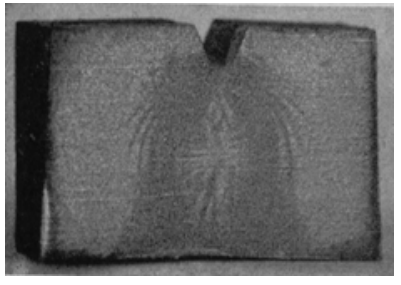

Fig. 7-Same as Fig. 6 showing $R_{B}$ hardness. $X 21 / 2$.

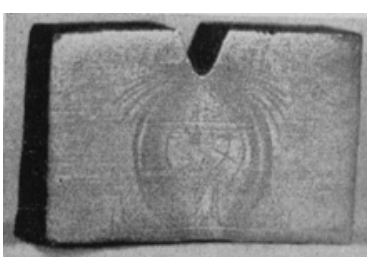

Fig. 9-Same as Fig. 8 showing $R_{B}$ hardness. $X 21 / 2$.
Fig. 2-Strain pattern in a 0.20 pet $C$ mild steel Charpy impact specimen partially deformed at $-75^{\circ} \mathrm{F} . \times 2 \frac{1}{2}$.

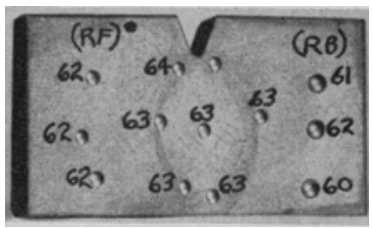

Fig. 6-Strain pattern near the surface of specimen shown in Fig. 5. X21/2.

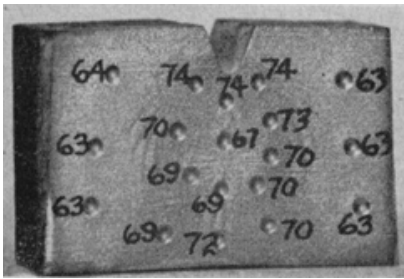

duce initial cleavages or break the specimen, Fig. 2, but by slightly increasing the impact load a similar specimen broke with 100 pct brittle fracture, Fig. 4 . The strain patterns in both specimens are essentially alike. Experience on many attempts was that the specimens either partially deformed without initial cracks or fractured completely. Any cracks that did develop were always ductile tears near the notch.

The series of strain patterns in Figs. 2 to 19 showed good correlation with the amount of bending or plastic deformation to which the specimen had been subjected. Also significant was the fact that higher stresses, and consequently more strain, existed near the longitudinal surface normal to the notch than in the corresponding center portion of the partially deformed specimens. Not only was there a difference in the amount of strain at the surface and center of the specimen, but the shape of the strain figure also changed, see Figs. 6, 8, 11, and 13. This illustrates the already known ${ }^{5}$ stress distribution in Charpy-type impact specimens wherein the stresses are more biaxial at the surface and triaxial near the center.

The sequence of strain in the Charpy-type impact specimen is also indicated. A small amount of initial plastic flow extends in a symmetrical convex manner from the bottom of the specimen to the base of the notch, Fig. 2, while the strain-free central por-

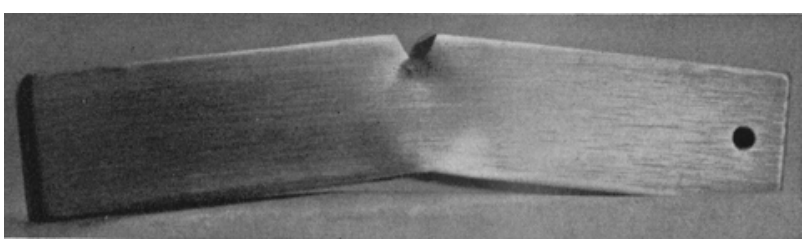

Fig. 10-Partial deformation in a mild steel Charpy impact specimen tested at $0^{\circ} \mathrm{F}, 25 \mathrm{lb}$ capacity. $\mathrm{X} 2$. Area reduced approximately 40 pct for reproduction.

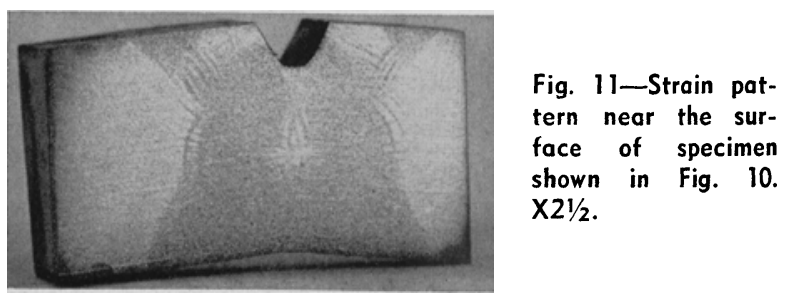

Fig. 12 - Same as Fig. 11 showing
hardness. $\times 21 / 2$.

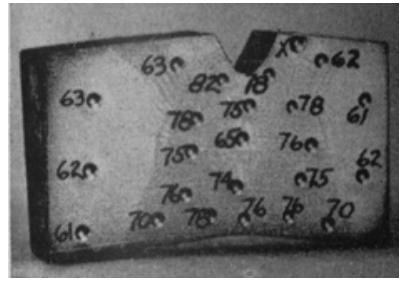

Fig. 8-Strain pattern in a section through central portion of specimen shown in Fig. $5.1 \frac{1}{2}$.

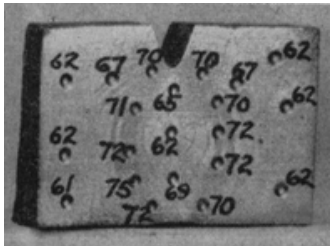

Fig. 13-Strain pattern in a section through central portion of specimen shown in Fig. 10 . $X 21 / 2$.

Fig. 14-Same os Fig. 13 showing $R_{B}$ hardness. $\times 21 / 2$.

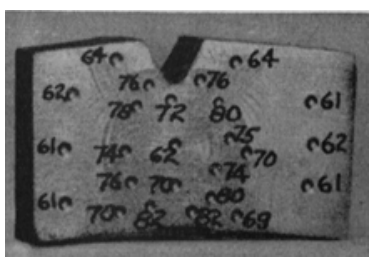


tion is probably stressed within the elastic limit. With increasing load and further bending, the strain pattern becomes more complex. Finger-like strain markings branch out and downward from the notch; the strained region at the bottom of the specimen increases due to compressive stresses, Fig. 8; and a band conforming to the shape of the notch, Fig. 13, appears. Finally, with very severe deformation, the entire region from the bottom of the specimen to the notch and a broad area following the contour of the notch shows plastic flow, Fig. 16.

The hardness of the dark etching region was determined and plotted directly on the various strain figures. There was little or no hardness increase with initial plastic flow, Fig. 3, but further deformation was accompanied by correspondingly higher hardness values, Figs. 9, 14, and 19. The hardness of the light etching, elastically deformed regions in the central portion of some of the strain figures was of the same order as the unstrained base metal at either end of the sectioned specimens, Figs. 3, 7, and 14 .

The dependence of impact transition energy on the yield phenomenon has been discussed previously. ${ }^{6}$ It was pointed out that within the region of greatest triaxiality of stresses, located somewhat back of the notch, the restraint to deformation and the temperature of the steel are such as to cause cleavage within the ferrite grains when the tensile stress normal to cleavage planes reaches an appropriate value. Microscopically, it was shown that flat "brittle" cleavages exist in the 100 pct brittle specimens tested at temperatures below the transition, Fig. 20. Within the transition range the "brittle" cleavages are restricted to the central portion of the fractured surface, Fig. 21, while above the transition, Fig. 22, no "brittle" portion exists and all the fracture facets were shown by subsequent micrographic examination to be distorted by cold work. The amount of brittle cleavage that is observed on fractured surfaces agrees with the observed strain patterns, in that below the transition, plastic flow is divorced from the area in which brittle fracture takes place, while within the transition, the amount of plastic deformation has increased as the elastically stressed regions where "brittle" cleavages could occur have become restricted. Above the transition, all the area under the notch showed plastic flow, as revealed by the strain figures, while microscopically, it was shown that the fracture facets were distorted.

\section{Summary}

Strain patterns can be developed to show the regions of plastic flow and elastic stress in Charpytype impact specimens of mild steel. An increase in hardness with increased plastic flow, as indicated by the strain etching, was shown. The strain patterns revealed more deformed metal near the surface than on a section through the central portion of the specimen, which illustrates the effect of a biaxial stress distribution at the surface and triaxial stresses at the center.

The amount of strain was correlated with the type of fracture over the transition energy range as follows:

1-A small amount of initial plastic flow extends in a convex manner from the base to the bottom of the notch, with strain free, elastically stressed metal between the symmetrical markings. This condition is representative of specimens tested at low tem-

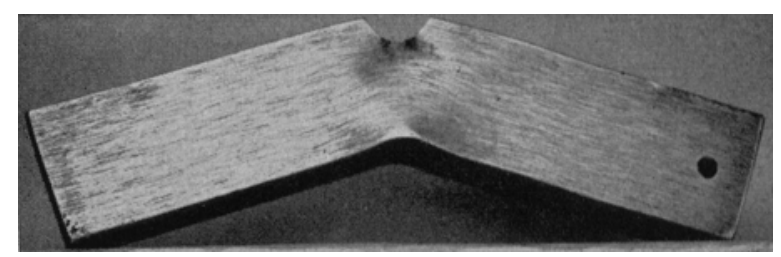

Fig. 15-Partial deformation in a mild steel Charpy impact specimen tested at $27^{\circ} \mathrm{F}, 60 \mathrm{lb}$ copacity. $\mathrm{X} 2$. Area reduced approximately 40 pet for reproduction.

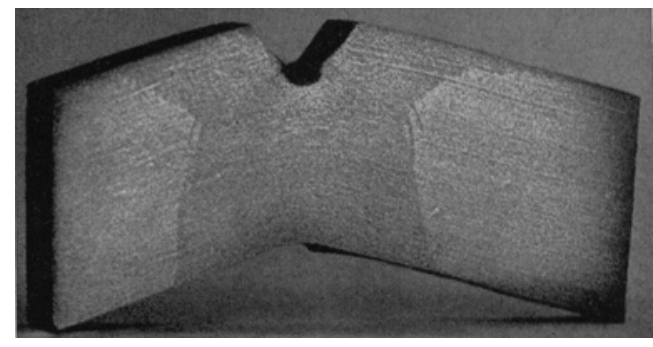

Fig. 16-Strain pattern near surface of specimen shown in Fig. $15 . \times 2 \frac{1}{2}$.

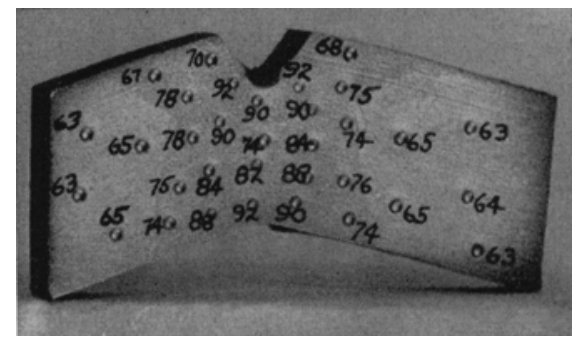

Fig. 17-Same as Fig. 16 showing $R_{B}$ hardness. $\mathrm{X} 2 \mathrm{1} / \mathbf{2}$.

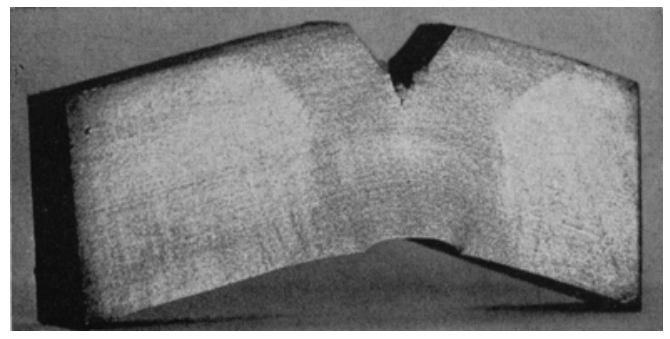

Fig. 18-Strain pattern in a section through central portion of specimen shown in Fig. 15. X21/2.

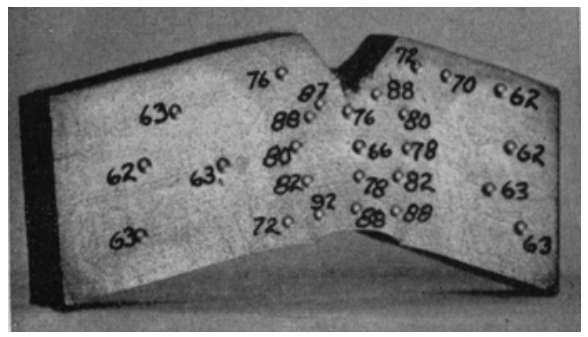

Fig. 19-Same as Fig. 18 showing $R_{B}$ hardness. $\mathrm{X} 2 \mathrm{1} / 2$.

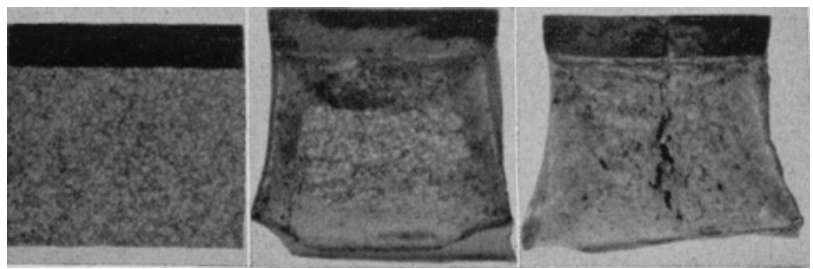

Fig. $20-100$ pct Fig. $21-30$ pet "brittle" cleavage. "brittle" cleavage.
Fig. $22-0$ pct

"brittle" cleavage. 
peratures, below the transition where fractures are 100 pet brittle.

2-Within the transition range, the increased deformation results in strain markings which branch out from the notch, and a larger strained area at the bottom of the specimen due to compressive stresses is obtained. The correspondingly smaller elastically stressed portion is characteristic of partially "brittle" fractures within the transition energy range.

3 -Above the transition temperature, the entire region from the bottom of the specimen to the notch, and a broad area following the contour of the notch, shows plastic flow. The 100 pct "ductile" fractures are characteristic of this energy level.

\section{Acknowledgment}

The author acknowledges his indebtedness to
M. Baeyertz, who conceived and initiated this study, and to Walter Craig, who supervised and encouraged the experimental work. Thanks are due to J. P. Sheehan for assistance, and to M. Hansen and the Armour Research Foundation for permission to publish these results.

\section{References}

${ }^{1}$ A. Fry: Stahl und Eisen (1921) 41, p. 1093.

2 J. D. Jevon: Journal Iron and Steel Inst. (1925) 111, pp. 191-204

${ }^{3}$ W. J. Harris, Jr., J. A. Rinebolt, and R. Raring: Welding Journal (September 1951) p. 417-S.

${ }^{4}$ Metals Handbook (1948) p. 391. Cleveland. A.S.M.

${ }^{5}$ M. Gensamer: Strength of Metals Under Combined Stresses (1941) pp. 18-20. Cleveland. A.S.M.

${ }^{6}$ M. Baeyertz, W. F. Craig, Jr., and E. S. Bumps: Trans. AIME (1949) 185, pp. 481-490; JourNAL of Metals (August 1949).

Technical Note

\title{
Diffusion of Silicon in Iron
}

\author{
by W. Batz, H. W. Mead, and C. E. Birchenall
}

A $\mathrm{T}$ temperatures between $1095^{\circ}$ and $1347^{\circ} \mathrm{C}, 13$ runs have been made on the diffusion of silicon in iron. In two of the runs the couple compositions were entirely within the $\gamma$ loop of the Fe-Si system; the base alloys contained 0.0 and 1.0 wt pct Si. The other runs in which the couples consisted of a 2.3 wt pct Si alloy welded to a 3.7 pct $\mathrm{Si}$ alloy were $\alpha$ phase throughout. The alloys were made by melting electrolytic iron and commercially pure silicon. Trace impurities were not determined.

The butt welded couples were diffused in an inert atmosphere of argon or hydrogen. After cooling, cuts of two mils or greater thickness were machined parallel to the weld interface. The chips were analyzed for silicon. When the concentration and distance data were examined on the conventional probability plot, ${ }^{1}$ no marked variation of the diffusion coefficient with concentration was indicated over the narrow composition ranges employed. Therefore, a single diffusion coefficient is recorded for each run in Table I. The temperatures and atmospheres of the diffusion anneal are listed along with the compositions of the base alloys.

For $\alpha$ iron the silicon diffusion coefficient is given by the equation:

$$
D=0.44 e^{-48,000 / R T}
$$

where $R$ is the gas constant and $T$, the absolute temperature. However, since the scatter in the data is fairly large, the activation energy may be in error by as much as 6000 cal per g-atom.

The two $\gamma$ iron points do not permit estimation of the activation energy with any reasonable certainty. They do indicate that the coefficients reported by Smithells ${ }^{2}$ and Jost, ${ }^{3}$ based on the work of Fry, ${ }^{4}$ are much too high.

Although very dilute solutions in iron of manganese, ${ }^{5}$ nickel, ${ }^{6}$ cobalt, $^{7}$ and molybdenum ${ }^{8}$ give dif-

W. BATZ, formerly Research Assistant, Metals Research Laboratory, Carnegie Institute of Technology, is now with the Research Laboratories, Jones \& Laughlin Steel Corp., Pittsburgh, H. W. MEAD, Junior Member AIME, is Research Associate, Metals Research Laboratory, Carnegie Institute of Technology, Pittsburgh, and C. E. BIRCHENALL, Junior Member AIME, formerly Member of Staff, Metals Research Laboratory, is now Assistant Professor of Chemistry, Princeton University, Princeton, N. J.

TN 123E. Manuscript, June 27, 1952.
Table I. Diffusion Coefficients of Silicon in $\alpha$ and $\gamma$ Iron

\begin{tabular}{clcc}
\hline $\begin{array}{c}\text { Composition } \\
\text { Range, } \\
\text { Wt Pct }\end{array}$ & $\begin{array}{c}\text { Annealing } \\
\text { Atmosphere }\end{array}$ & $\begin{array}{c}\text { Diffusion } \\
\text { Tempera- } \\
\text { ture, }{ }^{\circ}\end{array}$ & $\begin{array}{c}\text { DC } \\
\text { Coefficient, } \\
\text { Sq Cm } \\
\text { per Sec }\end{array}$ \\
\hline $0.0-1.0$ & Hydrogen & 1206 & $4.0 \times 10^{-10}$ \\
$0.0-1.0$ & Hydrogen & 1293 & $1.7 \times 10^{-9}$ \\
$2.3-3.7$ & Argon & 1095 & $1.5 \times 10^{-8}$ \\
$2.3-3.7$ & Argon & 1194 & $2.4 \times 10^{-8}$ \\
$2.3-3.7$ & Argon & 1201 & $4.2 \times 10^{-8}$ \\
$2.3-3.7$ & Argon & 1202 & $3.2 \times 10-8$ \\
$2.3-3.7$ & Hydrogen & 1249 & $5.0 \times 10^{-8}$ \\
$2.3-3.7$ & Hydrogen & 1255 & $5.7 \times 10^{-8}$ \\
$2.3-3.7$ & Hydrogen & 1284 & $1.3 \times 10^{-7}$ \\
$2.3-3.7$ & Hydrogen & 1300 & $9.0 \times 10^{-8}$ \\
$2.3-3.7$ & Hydrogen & 1306 & $1.1 \times 10^{-7}$ \\
$2.3-3.7$ & Hydrogen & 1344 & $1.2 \times 10^{-7}$ \\
$2.3-3.7$ & Hydrogen & 1347 & $1.3 \times 10^{-7}$ \\
\hline
\end{tabular}

fusion coefficients quite close to those obtained for self-diffusion in iron, the silicon values are considerably higher, though of the same order of magnitude. This seems to be consistent with the fact that the silicon atom is the only one of those listed here which is appreciably smaller than iron.

The authors are grateful to the Office of Naval Research for their support of this work under Contract N6ori-47, Task Order IV, Project NR 031-184, to J. K. Stanley and the Westinghouse Research Laboratories for the silicon alloys used, to several steel companies for the silicon analyses, and to C. Wells, of the Metals Research Laboratory, Carnegie Institute of Technology, for numerous suggestions during the course of the work.

\section{References}

${ }^{1}$ C. Wells: Atom Movements (1951) Chapter 2. A.S.M.

${ }^{2}$ C. J. Smithells: Metals Reference Book (1949) p. 405. Interscience. Pub. Co.

${ }^{3}$ W. Jost: Diffusion (1952) p. 223. Academic Press.

${ }^{4}$ A. Fry: Stahl und Eisen (1923) 43, p. 1039.

"C. Wells and R. F. Mehl: Trans. AIME (1941) 145, p. 315 .

${ }^{\circ}$ C. Wells and R. F. Mehl: Trans. AIME (1941) 145, p. 329 .

${ }^{7}$ M. F. Hawkes and R. F. Mehl: Trans. AIME (1947)

172, p. 467; Metals Technology (August 1947).

${ }^{8}$ J. L. Ham: Trans. A.S.M. (1945) 35, p. 331. 